\title{
Cooperativismo e cooperativa no desenvolvimento da citricultura na região de Araraquara
}

COSTA, Vera Mariza Henriques de Miranda ${ }^{1}$

Resumo: O presente artigo é parte de Tese de Doutoramento em Economia, desenvolvida sobre cooperativismo e cooperativas ligadas à produção agrícola na "Região de Araraquara". Partindo-se do suposto da flexibilidade das cooperativas de assumirem a conformação dos ambientes que as abriga, foi desenvolvido estudo de caso de uma cooperativa agrícola mista, na tentativa de identificar o potencial desse tipo de empresa como veículo de planejamento e organização de produtores de citros, em esfera regional. Abrangeu a caracterização do desenvolvimento da empresa no contexto da região, a análise dos avanços alcançados e dos problemas enfrentados. Foram identificadas potencialidades da cooperativa e dificuldades desse tipo de organização, diante da concorrência, da falta de solidariedade que se esperava dos produtores agrícolas e sem o apoio do Estado.

Palavras-chave: Cooperativas; Citricultura; Região de Araraquara.

\section{COOPERATIVISM AND COOPERATIVE IN THE DEVELOPMENT OF CITRICULTURE IN ARARAQUARA REGION}

\begin{abstract}
This paper is part of a $\mathrm{PhD}$ Thesis in Economics, developed on cooperativism and cooperatives linked to agricultural production in the "Araraquara Region". Based on the assumption of the flexibility of the cooperatives to assume the conformation of the environments that house them, a case study of a mixed agricultural cooperative was developed in an attempt to identify the potential of this type of company as a vehicle for the planning and organization of citrus producers in the regional sphere. It covered the characterization of the company's development in the context of the region, the analysis of the progress achieved and the problems faced. Potentialities of the cooperative and difficulties of this type of organization were identified, given the competition, the lack of solidarity expected of the agricultural producers and without the support of the State.
\end{abstract}

Keywords: Cooperatives; Citriculture; Araraquara Region.

${ }^{1}$ Docente do Programa de Mestrado Profissional em Engenharia de Produção da Universidade de Araraquara - UNIARA e Pesquisadora FUNADESP. 


\section{Cooperativismo e cooperativa no desenvolvimento...}

\section{INTRODUÇão}

O presente artigo foi estruturado a partir de Tese de Doutoramento em Economia (MIRANDA, 1973) defendida em 1974 na Faculdade de Filosofia, Ciências e Letras de Araraquara (FFCLA), atualmente Faculdade de Ciências e Letras (FCL) da Universidade Estadual Paulista "Júlio de Mesquita Filho" - UNESP, Campus de Araraquara.

Decorridos 43 anos, avaliou-se oportuna a apresentação de resultados do referido trabalho, por ocasião do bicentenário da cidade de Araraquara, uma vez que abordara questões referentes ao município e àregião em que este se insere.

Nos termos da referida tese, ela foi elaborada num momento em que as preocupações com o desenvolvimento constituíam uma das questões mais relevantes colocadas pela Ciência Econômica e pelas demais Ciências Sociais, em suas investigações teóricas e na aplicação prática de suas conclusões. Na avaliação das condições do desenvolvimento do país, os estudos, em sua grande maioria, priorizavam o processo de industrialização, ficando a agricultura relegada a um segundo plano, sendo principalmente lembrada apenas quando discutida sua participaçãono processo de desenvolvimento econômico ${ }^{1}$

Aexperiência acumulada no Centro de Sociologia Industrial e do Trabalho(CESIT), coordenado pelo Prof.Florestan Fernandes, na Faculdade de Filosofia, Ciências e Letras da Universidade de São Paulo (FFCL/USP), na primeirametadedosanos 1960, estimuloua estruturaçãode um projeto de estudo de cooperativas ligadasà agricultura.

Partiu-se da motivação de que, se procedia estudar a formação da empresa industrial em São Paulo, fazia também sentido desvendar o processo de constituição de empresas na agricultura, tomando Araraquara-SP como universo da investigação. Dessa perspectiva foram iniciados os estudos sobre o cooperativismo e as cooperativas nas atividades agrícolas desse município, cujos resultados deram suporte ao desenvolvimento da já referida Tese de Doutorado (MIRANDA, 1973), partir da qual foi estruturado este artigo.

Foram estudadas para a tese, no período de 1968 a 1972, três cooperativas: de citros, de cana e de café. Procurava-se avaliar esse tipo de empresa, vinculada a produtos agrícolas com presença e significado econômico para a região. Para este artigo foi escolhida a de citros, em razão de que as ações nela desenvolvidas deixaram marcas mais evidentes no desenvolvimento da atividade agroindustrial na Região de Araraquara e para a formulação de reflexões sobre possibilidades e limites da atuação de cooperativas nas atividades agroindustriais.

As possibilidades de colocação no mercado externo de produtos, se não agrícolas, agro-industriais, se mostravam bastante favoráveis, no momento em que foi desenvolvida a investigação. Este fato, inclusive, levava a que se conjecturassea possibilidade de um "novo primário exportador"2, evidentemente, agora, com características e funções diversas daquelas observadas no Brasil, anteriormente a 1930. Assim sendo, resultados de investigações que contribuíssem paraa formulação de políticas voltadas ao desenvolvimento da agricultura, bem como toda a iniciativa que viabilizasse a execução do planejamento do setor, teriam seus objetivos justificados.

Nesse contexto, foi aventada a possibilidade das cooperativas de produção, ligadas à agricultura, virem a desempenhar as funções de veículo de planejamento com vistas ao desenvolvimento desse setor. Assim sendo, a investigação apoiou-se na hipótese da possibilidade das cooperativas serem incorporadas ao instrumental de Política Econômica, visando ao desenvolvimento econômico do setor primário, em esfera regional.

Para dar suporte teórico conceitual à investigação, foi desenvolvido estudo do pensamento cooperativista em seu processo evolutivo e em suas manifestações teóricas e doutrinais. Uma vez que se aventava a possibilidade de uso das cooperativas para o planejamento, fazia-se necessário, também, julgar a compatibilidade dos princípios que regem essa modalidade de empresa e dão conteúdo à doutrina, frente a realidades concretas, diversas daquelas em que esses princípios tiveram origem. No cumprimento dessa necessidade, na tese, procedeu-se à avaliação do processo evolutivo do cooperativismo no Brasil, com atenção especial para o estado de São Paulo. Essa avaliação permitiu identificar as potencialidades das cooperativas de produção para o desenvolvimento planejado de atividades do setor primário, fornecendo o suporte "empírico" para a investigação

10 artigo de Johnston e Mellor (1961) - um clássico na discussão das funcões da agricultura para o desenvolvimento econômico - refere-se a: 1. Transferência de
recursos produtivos - força de traballo do setor agrícola para o não-agrícola e formačao de capital; 2. Criação de mercado; 3. Mudança nos termos de intercâmbio, 4. Geraçăo de divisas; 5 . Producăa de matetrias-primas e de alimentos. Castro (1969), ao analisar o cumprimento das funcóos da agricultura brasileira no proces de desenvolvimento econômico, sintetiza as funçoôes básicas nas seguintes: 1 Gerãã e permanente ampliação de um excedente de alimentos e matérias primas; 2 . Liberação de mão de obra; 3 . Criação de mercadoa; 4 . Transsferência de capitais.

economia brasileira no século XIX e ińíio do XX. Com o desenvolvimento das attividajes induâmica era dada pelo crescimento das exportações e que marcou a

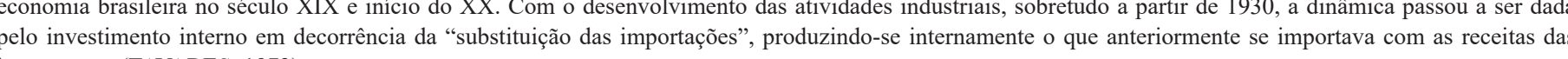
importações (TAVARES, 1973). das cooperativas com atuação na Região de Araraquara.

Foi a seguinte a questão norteadora da investigação: "Quais as possibilidades de cooperativas que reúnem produtores agrícolas de produtos específicos intervirem sobre a organização de atividades produtivas de uma determinada região"? O estudo de caso de uma cooperativa de citros, tratado neste artigo, pretendeu responder, em parte, a essa questão. A justificativa para a avaliação da cooperativa da perspectiva de um estudo de caso requereu a caracterização da região em que ela se inseria, designada de Região de Araraquara, correspondente a então Microrregião Homogênea 242 do IBGE (IBGE, 1970).

A quase totalidade das considerações apresentadas neste artigoreproduz resultados, análises e avaliações extraídos e sintetizados a partir da tese que lhe deu origem. A região objeto do estudo foi tratada em conformidade com suas características apreendidas nos anos 1970, quando foi desenvolvida a investigação. Da mesma forma, mantiveram-se as informações e as reflexões conectadas ao contexto histórico e geográfico em que foram investigadas e a postura doutrinária sobre cooperativas expressas naquele momento. No entanto, muitos dos questionamentos sobre as efetividades propostas para as cooperativas, sobretudo as relativas à possibilidade de solidariedade e cooperação entre os produtores, continuam presentes, mais recentemente associadas a reflexões emanadas dos princípios da Economia Solidária, que tem em Singer (2002) um expoente.

Cooperativismo e empresas cooperativas

As cooperativas podem ser definidas como sociedades de pessoas, organizadas a partir dos "Princípios dos Pioneiros de Rochdale", formulados no final do século XIX, que visam além de suprir seus membros de bens e serviços, realizar determinados programas educativos e sociais. Assim sendo, suas finalidades extrapolam objetivos apenas de ordem econômica e se voltam à correção do meio no qual se desenvolvem (ROJAS CORIA, 1961; PINHO, 1962).

A avaliação das considerações e análises de pensadores e historiadores do cooperativismo, dentre os quais Mladenatz (1944), Fauquet (1965), Lambert (1964), Lavergne (1962), Guelfat (1966) permite a formulacão de algumas reflexões sobre princípios teóricos e doutrinais envolvidos. A ausência de uma Teoria e a fragilidade da Doutrina Cooperativista são aspectos a serem considerados, quando buscadas as bases de sustentação da empresa cooperativa e as explicações para a adaptabilidade dela aos ambientes em que se insere, superando, de certa forma, a rigidez de seus princípios doutrinários originários dos Pioneiros de Rochdale.

Guelfat (1966) reconhece as contribuições de Gide, Lavergne, Fauquet, Lassere, Tougan-Baranovsky, De Brouckere, Grünfeld, Mariani, Valenti, Webb, Cole etc., para o desenvolvimento do cooperativismo; no entanto, avalia que os trabalhos deles constituem contribuições parciais e incompletas de uma Teoria Econômica Cooperativista, pois não estudaram o Cooperativismo do ângulo da Ciência Econômica. Valendo-se das palavras de Tougan-Baranovsky, proferidas no início do século XX, em "Versl'avenir meilleur", Guelfat (1966, p. 20) afirma: "Se a prática do movimento obtém a cada ano rápido sucesso, suscita novas formas de ação e amplia o círculo da população atingida, a teoria da cooperação não apenas não progride, mas por assim dizer não existe ainda".

Assim, à fragilidade da Doutrina deve-se acrescentar a inexistência de uma Teoria Cooperativista. De fato, os pensadores cooperativistas não foram capazes de organizar um corpo teórico consistente a partir de suas pretensões doutrinárias. Uma vez que a Doutrina Cooperativista não gerou uma Teoria que the fosse correspondente, suas justificativas são feitas de forma fluida. Apoiada sobre princípios híbridos, suas possibilidades de explicação e atuação sobre a realidade se vêm limitadas, dada a ausência de instrumental teórico próprio.

Esta constitui uma das razões pelas quais as pretensões da Doutrina Cooperativista se apresentam irrealizáveis e, até mesmo, utópicas. A viabilidade de funcionamento das empresas cooperativas, regidas pelos princípios cooperativistas, interpretados ortodoxamente, é duvidosa; suas possibilidades ficam na dependência de sua adequação à realidade em que se inserem e mesmo sujeitas a elas.

No entanto, é justamente a inexistência de uma teoria que lhe dê suporte que torna a empresa cooperativa, concretização da Doutrina Cooperativista, paradoxalmente, uma organização flexível. A prova dessa flexibilidade é dada pela presença das empresas cooperativas tanto nos países desenvolvidos com nos subdesenvolvidos, nos de estrutura capitalista ou socialista (PINHO, 1963a e 1966). A partir dessa flexibilidade é pensada a possibilidade das cooperativas se tornarem um veículo do planejamento e do desenvolvimento (BONNER, 1960; DESROCHE, 1964; PINHO, 1963b, 1964a, 1964b e 1973).

Lambert (1912-1977) e Desroches (1914-1994) foram autores preocupados com a "atualização" da doutriRevista Brasileira Multidisciplinar - ReBraM vol 20, (supl.) n.1 - Araraquara 200 anos 
na cooperativista e, sobretudo, com a possibilidade da utilização das cooperativas pelo planejamento econômico (LAMBERT, 1964; LAVERGNE, 1962).

Para Pinho (1973, p. 23) os estudos doutrinários refletiam, na segunda década do século XX, a tendência da Ciência Econômica que se orientava "....cada vez mais para a ação e busca de bases concretas para atender às necessidades da política econômica e do planejamento".

\section{Metodologia}

A pesquisa que deu suporte ao presente artigo é classificada, segundo Turrione e Mello (2012), Berto Nakano (2000), Nakano (2010), Martins (2010), Cauchick Miguel (2005) e Yin (2005) como:exploratóriadescritiva, longitudinal, com abordagem qualitativa e desenvolvida por meio de um Estudo de Caso. Exploratória-descritiva na medida em que buscou maior familiaridade com o tema, bem como a descrição e o delineamento das principais características do fenômeno, envolvendo observação sistemática, técnicas e instrumentos diversos e padronizados para coleta de dados. Longitudinal dado que, por meio de documentos, foi avaliada a evolução da cooperativa objeto da investigação, no contexto do que se designou Região de Araraquara. A abordagem foi qualitativa, o que implicou no delineamento do contexto e do ambiente da pesquisa e a investigação foi desenvolvida em proximidade com os entrevistados, buscando-se a interpretação deles. Foi definido como tipo ou estratégia de pesquisa o estudo de caso, uma vez que, nos termos de Yin (2005), as fronteiras entre o fenômeno e o contexto não se apresentavam claramente definidas. Tratava-se, ainda, de uma análise aprofundada de um caso, que permitisse o seu amplo e detalhado conhecimento. Assim sendo, o objeto do estudo foi escolhido pelas suas características e especificidades e, para captar a variedade de evidências, foi desenvolvida observação direta e indireta; foram levantados documentos referentes à empresa material divulgado pela imprensa, disponíveis na cooperativa estudada. A observação direta foi desenvolvida, inicialmente, pormeiode entrevistasinformaise, após maiorfamiliaridadecomaentidade, de roteirosestruturados

A investigação na cooperativa foi autorizada pelos gestores da empresa que se comprometeram a disponibilizar informações e documentos- estatutos, regulamentos, atas etc. - e se dispuseram a relatar os processos de formação e desenvolvimento dela e a participar da pesquisa como entrevistados.

As visitas à cooperativa, o levantamento de dados e a realização das entrevistas foram feitos no período de 1965 a 1970, já num momento de declínio das atividades da empresa.No entanto, ainda foi possível, através dos documentos analisados e das entrevistas realizadas, captar a euforia do processo de instalação e de desenvolvimento inicial, bem como identificar as dificuldades enfrentadas, justamente no período em que foram levantadas as informações.

A fim de manter o sigilo, deliberou-se, na ocasião, não divulgar o nome da cooperativa analisada, preferindose manter, neste momento, a deliberação tomada naquelaocasião.

Asinformações sobre a Região de Araraquarae suas características, sobretudo considerando seu perfil agrícola, no contexto do estado de São Paulo, foram buscadas em livros, documentos e em fontes oficiai (CORREA, 1968; IBGE, 1970; IEA, 1971; SÃO PAULO, 1963 e 1967; SÃO PAULO, 1972). Muitos do dados, não publicados, estavam disponíveis para coleta e organização em Secretarias e Departamento do Estado, dentre os quais as Secretarias da Agricultura, do Planejamento e no DEESP (Departamento de Estatística do Estado de São Paulo)

As informações sobre o cooperativismo e as cooperativas do estado de São Paulo, necessárias para que fossem "situadas" as três cooperativas selecionadas para análise, das quais uma é objeto deste artigo, foram levantadas no então Departamento de Assistência ao Cooperativismo (DAC) da Secretaria da Agricultura do estado de São Paulo (DAC, 1941, 1943, 1951a, 1951b) e no INCRA (1973).

Constituíram fontes de informação relevantes para a caracterização e avaliação da cooperativa estudada, no contexto do estado de São Paulo e tendo em vista as características do cooperativismo e das cooperativas no Brasil os trabalhos de Arruda (1972), Pinho (1964a, 1965) e do Instituto Nacional de Colonização e Reforma Agrária - INCRA (1973)

O suporte teórico sobre cooperativismo foi levantado em bibliografia específica, tratada na seção referente a Cooperativismo e Empresa Cooperativa.

\section{A empresa cooperativa e a região de Araraquara}

$\mathrm{O}$ foco da pesquisa, para o desenvolvimento do estudo de caso, foi uma cooperativa agrícola mista que reu- nia produtores de citros e o universo mais amplo foi delimitado a partir da área de ação da referida cooperativa. Em razão da disponibilidade de dados por agregação regional foi priorizada região delimitada pelo Instituto Brasileiro de Geografia e Estatística (IBGE) sob a designação de MicrorregiãoHomogênea 242 e, no contexto da investigação, designada de "Região de Araraquara" (IBGE, 1970)

Caracterizaçãoe delimitação da "Região de Araraquara" - Microrregião Homogênea 242

Dado que a investigacão estava centrada nas atividades agrícolas, uma opção seria delimitar a região objeto do estudo a partir das DIRA's (Divisão Regional Agrícola). No entanto, segundo informações de técnicos da DIRA de Ribeirão Preto, os critérios orientadores da constituição das regiões agrícolas apoiavam-se muito mais nas possibilidades de comunicação entre os municípios componentes e a sede da região, do que na estrutura e composição da produção agrícola e agropecuária regional.

Assim sendo, foi buscado outro critério de recorte regional que viabilizasse, dentre outros, a obtenção de dados e informações, chegando-se, assim à escolha da Microrregião Homogênea 242. Os 17 municípios dessa Região estavam distribuídos por três Regiões Agrícolas: Araraquara, São Carlos e Taquaritinga, abrangendo a totalidade dos municípios componentes das Regiões Agrícolas de Araraquara e de São Carlos e três dos nove municípios da Região Agrícola de Taquaritinga. Da Região Agrícola de Araraquara faziam parte 9: Araraquara, Américo Brasiliense, Boa Esperança do Sul, Dobrada, Matão, Nova Europa, Rincão, Santa Lúcia e Tabatinga. Da Região Agrícola de São Carlos, 5: São Carlos, Descalvado, Dourado, Ibaté e Ribeirão Bonito. Da Região Agrícola deTaquaritinga, 3: Borborema, Ibitinga e Itápolis. Incluída, nos anos 1970 na Região Administrativa de Ribeirão Preto (em 1973, 6 6 Região Administrativa), a Microrregião Homogênea 242 abrangia as Sub-Regiões de Araraquara e de São Carlos, respectivamente as então sub-regiões números 7 (com exceção do município de Cândido Rodrigues) e 8.

Quando de sua fundação, em 1957, de acordo com documentos da cooperativa, sua área de atuação abrangia os seguintes municípios: Araraquara (incluindo, Santa Lúcia e Américo Brasiliense, então distritos de Araraquara) ${ }^{1}$, Boa Esperança do Sul, Descalvado, Dourado, Ibaté, Ibitinga, Itápolis, Matão (incluindo o então distrito de Dobrada), Nova Europa, Ribeirão Bonito, Rincão, São Carlos e Tabatinga, todos estes pertencentes à Microrregião 242; e mais: Fernando Prestes, Guariba, Bocaina, Jaboticabal, Monte Alto, Porto Ferreira, Santa Adélia e Taquaritinga.

Apesar da área de ação da cooperativa estudada não se identificar totalmente com a referida microrregião, no entanto, as propriedades agrícolas dos associados evidenciavam alta concentração nela. Razão vinculada à possível aplicação dos resultados da pesquisa, focada na possibilidade da cooperativa vir a exercer papel relevante, a partir de uma política com vistas ao desenvolvimento do setor agrícola, reforçou a delimitação geográfica da área de influência da cooperativa estudada à Microrregião Homogênea 242, esta institucionalmente definida. Caso concretizada a viabilidade da cooperativa atuar como veículo de planejamento, a própria delimitação de sua área de influência, em consonância com os critérios de divisão administrativa, poderia efetivar autilização dos "canais de transmissão" de que se vale o corpo administrativo. Assim, ficaria facilitada, uma vez que viável, a atuação da cooperativa como "polo" de desenvolvimento regional.

A área de ação da cooperativa estudada tivera seu desenvolvimento impulsionado ao ser alcançada pela rota do café. Sua evolução prosseguira através da produção canavieira e açucareira, mostrando-se seu desenvolvimento promissor no que se refere à produção de cítricos.

$\mathrm{Na}$ "Região de Araraquara", da mesma forma que no município de Araraquara, evidencia-se o declínio da economia cafeeira ao mesmo tempo em que se elevava a produção canavieira e citrícola (sobretudo de laranja).

Destaca-se, durante todo o período analisado (1955-1970), no que se refere à agricultura, na "região" e no município de Araraquara, a produção de: cana, café, laranja, arroz, feijão, milho e algodão, com elevada participação no valor da produção agrícola municipal e regional, conforme Tabela 1

Cabe observar, em relação ao município e à região, a participação crescente da cana de açucar, de 1955 a 1965, a redução do café, em todo o período analisado - tanto no município quanto na região - e o crescimento da participação da laranja, mais intenso no município que na região.

Durante o período analisado as informações referentes aos municííios de Santa Lúcia e Américo Brasiliense foram tratadas agregadas ao municíipio de Araraquara

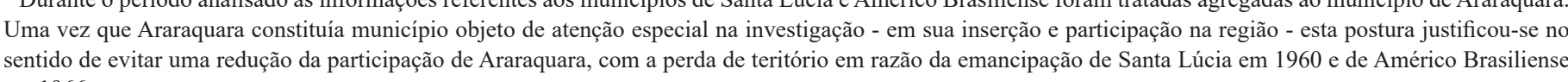
em 1966 
Tabela 1 - Participação de alguns produtos no Valor da Produção Agrícola de Araraquara e da Região de Araraquara $(1955,1960,1965,1970)$

\begin{tabular}{|c|c|c|c|c|c|}
\hline \multirow[t]{2}{*}{ PRODUTOS } & ANOS & \multirow[t]{2}{*}{1955} & \multirow[t]{2}{*}{1960} & \multirow[t]{2}{*}{1965} & \multirow[t]{2}{*}{1970} \\
\hline & $\begin{array}{c}\text { ARARAQUARA } \\
\text { REGIÃo }\end{array}$ & & & & \\
\hline \multirow[t]{2}{*}{ CANA } & ARARAQUARA* & 50,02 & 57,14 & 73,39 & 44,77 \\
\hline & REGIÃO & 18,80 & 31,51 & 47,62 & 43,01 \\
\hline \multirow[t]{2}{*}{ CAFÉ } & ARARAQUARA & 27,65 & 10,43 & 5,97 & 3,94 \\
\hline & REGIÃO & 49,88 & 23,32 & 13,31 & 7,21 \\
\hline \multirow[t]{2}{*}{ LARANJA } & ARARAQUARA & 2,90 & 3,14 & 10,23 & 27,88 \\
\hline & REGIÃO & 1,66 & 1,68 & 4,12 & 9,93 \\
\hline \multirow[t]{2}{*}{ ARROZ } & ARARAQUARA & 7,16 & 12,07 & 2,58 & 3,72 \\
\hline & REGIÃO & 9,63 & 14,16 & 9,55 & 7,05 \\
\hline \multirow[t]{2}{*}{ MILHO } & ARARAQUARA & 6,70 & 6.97 & 3,19 & 6,89 \\
\hline & REGIÃO & 8,82 & 10,31 & 6,42 & 7,93 \\
\hline \multirow[t]{2}{*}{ ALGODÃO } & ARARAQUARA & 0,57 & 1,30 & 0,83 & 2,49 \\
\hline & REGIÃO & 2,54 & 6,27 & 7,31 & 5,86 \\
\hline
\end{tabular}

* No período analisado, os valores referentes a Araraquara abrangem os municípios de Santa Lúcia e Américo Brasiliense, distritos de Araraquara, respectivamente até 1960 e 1966.

Fonte: A autora a partir de informações não publicadas, disponíveis no DEESP.

\section{A Cooperativa de citricultores: idealismo, dificuldades e legado para a região}

A cooperativa selecionada para investigação foi fundada em 1957 como cooperativa de citricultores, passando a agrícola mista em 1962.

Dado o desenvolvimento da citricultura na Região de Araraquara e no entorno de Limeira, Bebedouro e Araras e considerando-se as possibilidades de exportação de cítricos - principalmente de laranja - sobretudo para o mercado europeu, o então governador do estado de São Paulo, Jânio Quadros, manteve contato com citricultores das regiões mencionadas, sugerindo-lhes sua organização em cooperativas, com vistas à produção para a exportação. Assim, visualizava-se a possibilidade de, através das cooperativas, aperfeiçoar a produção de laranja, alcançando a qualidade exigida pelo mercado externo, que oferecia preços promissores.

Tendo em vista as exigências de qualidade da fruta, expressa em cor, sabor, facilidade para ser descascada, impostas pelo mercado externo, fazia-se necessária a assistência técnica ao produtor e, dessa forma, a cooperativa apresentava-se como locus privilegiado para a condução de um processo de melhoria do produto.

A cooperativa nasceu, então, tendo por finalidade interferir sobre o processo de produção (estrito senso) de citros, visando à melhoria da qualidade da fruta produzida, atendendo aos padrões exigidos pelo mercado externo. Constituía, ainda, seu objetivo, elevar a posição do citricultor, através de sua agregação no "momento" da comercialização. De fato, os objetivos fundamentais e mais amplos da referida cooperativa repousavam sobre a intervenção no próprio processo de produção, uma vez que os resultados obtidos através de melhorias técnicas introduzidas (adubação, utilização de inseticidas etc.) necessariamente resultariam em condições que contribuiriam para a melhoria da própria condição de comercialização.

Ao entrar na cooperativa, a laranja era selecionada, passando por processo de classificação. De acordo com a "qualidade" do produto entregue, o produtor recebia "pontos" que correspondiam às próprias possibilidades de comercialização do bem que produzira. A partir daí a fruta entregue não mais era "individualizada", ou seja, não mais importava a quem "pertencia" em sua origem. A laranja de melhor qualidade era canalizada para o mercado externo sendo o restante, o "refugo", comercializado internamente. Os resultados eram igualmente distribuídos para o conjunto dos cooperados.

Tanto na esfera da produção quanto da comercialização fazia-se presente a interferênciapositiva da cooperativa. Em razão de sua atuação, foi criada a possibilidade de desenvolvimento "racional" da cultura cítrica, com vistas à elevação da produtividade do agricultor e melhoria da qualidade da fruta produzida. Sua influência manifestava-se diretamente sobre a produção, fornecendo assistência técnica e logística ao produtor, desde à orientação no plantio até à distribuição da laranja in natura, inclusive incumbindo-se da contratação da mão de obra necessária para a colheita na propriedade do produtore do transporte da área agrícola para a sede da entidade.

Através da cooperativa apresentava-se a possibilidade de redução, para o produtor, dos custos de comercialização, reunindo a laranja produzida por seus associados e colocando-a diretamente no mercado. Dessa forma evitava-se a interferência de intermediários e eram propiciadas condições favoráveis à comercialização em escala, com redução dos custos e com reflexos evidentes, na criação de "poder de barganha" para a obtenção, dentre outros, de preços favoráveis.

Produzida a fruta "com qualidade" sua comercialização, através da cooperativa, estava praticamente garantida, como também estariam garantidos ao produtor preços superiores aos que ele obtinha no mercado interno. Dispondo de um moderno e bem aparelhado packing-house e tendo sido os preços de exportação altamente remuneradores nos primeiros anos, o produtor associado recebeu o correspondente a três vezes o obtido pelo não associado.

Dos trinta e dois citricultores que fundaram a cooperativa, dezoito $(52.5 \%)^{1}$ tinham suas propriedades localizadas no município de Araraquara ${ }^{2}$, sendo que as propriedades de vinte e seis $(81,2 \%)$ localizavam-se na Microrregião Homogênea 242.

Apesar de não ser a cultura de cítricos o principal produto dessa Microrregião, conforme Tabela 1, evidenciase a tendência de redução da importância do café em favor da cana de açúcar - fazendo-se gradativamente presente a citricultura, sobretudo no município de Araraquara.

Realmente, de início, os "negócios" da cooperativa mostraram-se promissores, apesar das dificuldades financeiras encontradas quando da sua instalação.

O apoio prometido por parte do governo do Estado, na realidade, não chegou a efetivar-se, não tendo passado de "um apoio teórico", segundo dirigente da cooperativa. De acordo com declaração de um dos

membros da diretoria da empresa na época, o financiamento obtido junto ao Banco do Estado de São Paulo deveria ser amortizado em 120 dias - prazo absolutamente irrisório para o financiamento de qualquer atividade produtiva e, mais ainda, em se tratando de atividade agrícola.

No entanto, o entusiasmo dos organizadores, encabeçado por um produtor, conhecedor e adepto dos princípios cooperativistas, foi capaz de conduzir à superação das dificuldades iniciais. Um barracão foi alugado e obteve-se um financiamento do Banco do Brasil. Através de crédito especial, o maquinário necessário para o processamento da laranja foi encomendado.

Assim, já em 1957, a cooperativa organizava-se no sentido da comercialização em comum das frutas de seus cooperados, tendo neste ano realizado entregas para Fisher $\mathrm{S} / \mathrm{A}^{3}$ e, apesar da quase total ausência de apoio, em 1959 já realizava exportação direta.

Dadas as condições de receptividade que o produto exportado pela cooperativa adquirira no exterior, refletindo-se em preços vantajosos para o produtor, o ingresso na cooperativa tornava-se estimulante, o que fica evidente pelo crescimento de cooperados apresentado no Gráfico 1.

A expansão dos cooperados ocorria não apenas nos municípios componentes da área de ação de cooperativa e da Microrregião Homogênea 242, mas também por outros, no entorno desta. O principal estímulo estava nos altos preços obtidos pela cooperativa no exterior, bem superiores aos praticados no mercado interno.

Desta forma, ao oferecer ao produtor preços vantajosos, desde que a fruta entregue por ele correspondesse às exigências do exterior, a cooperativa interferia no processo de produção de laranja. Dessa formaa "Região de Araraquara" passou a constar, com destaque, das informações sobre comercialização externa da laranja.

Até 1957 destacavam-se, como as maiores contribuintes para a exportação de laranja, as "regiões"de Li meira, Bebedouro, Araras e Pitangueiras. A partir de 1958 não apenas a "Região" de Araraquara é arrolada ao lado das anteriormente citadas, como também a cooperativa aqui analisada passa a constar dos noticiários de jornais referentes à exportação de cítricos.

É verdade que, apesar da fundação da cooperativa ter ocorrido por iniciativa de citricultores da região, encabeçados por um líder cooperativista, também citricultor, sem qualquer diagnostico prévio ou estudo de viabilidade para a implantação da empresa, a iniciativa foi, inicialmente, muito bem sucedida.

É possível que inclusive esta porcentagem fosse mais alta uma vez que não foi possivel determinar o local de propriedade de $18,7 \%$ dos cooperados que fundaram a cooperativa.

'Neste ano Santa Lúcia e Américo Brasiliense eram distritos de Araraquara, tendo-se desmembrado, respectivamente, em 1960 e 1966.
'Empresa que daria origem à Citrosuco sediada em Matão-SP.

Revista Brasileira Multidisciplinar - ReBraM vol 20, (supl.) n.1 - Araraquara 200 anos 
Cooperativismo e cooperativa no desenvolvimento.....

Figura 1 - Evolução do número de cooperados da Cooperativa de Citricultores(Agrícola Mista) estabelecidos em Araraquara* e na MicrorregiãoHomogênea 242 (1957-1970).

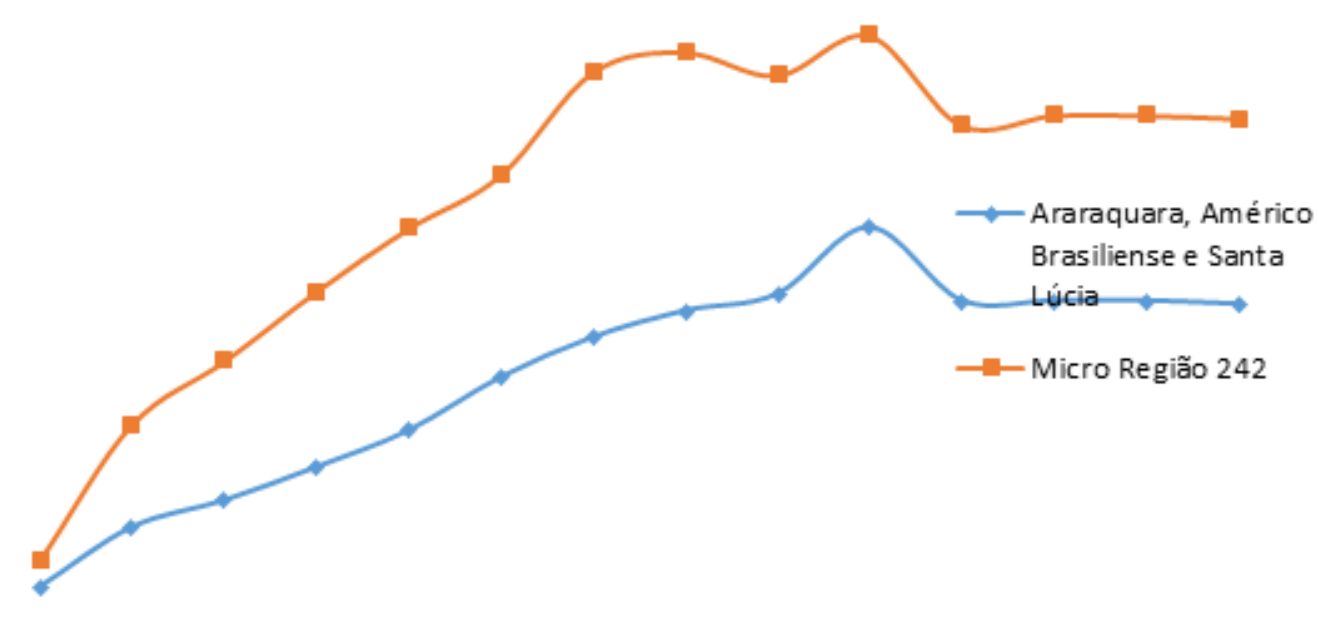

Santa Lúcia e Américo Brasiliense, o primeiro após 1960 e o $2^{\circ}$ após 1966, tornaram-se municípios, deixando de ser distritos de Araraquara. Neste gráfico continuam agregados durante todo o período.

Fonte: A autora a partir de documentos da Cooperativa.

É verdade, ainda, que a solução cooperativista para a laranja parecia ser bem recebida, tendo sido aventada durante o período que antecipou a fundação da empresa e comentada por jornais da época.

É verdade, também, que a produção da laranja paulista encontrava-se em ascensão, bem como se evidenciava a tendência de ampliação da citricultura na região estudada, conforme informações da Figura 1.

No entanto, mesmo contando com uma situação inicial favorável, em pouco tempo os efeitos da ausência de um diagnóstico orientador das atividades da empresa - a partir do qual tornar-se-ia possível esboçar o prognóstico de seu funcionamento - e o fato das atividades da cooperativa não estarem incluídas em um plano mais amplo por parte do Estado, se fizeram sentir. Além do mais, o crédito de confiança conferido às potencialidades da empresa cooperativa, como entidade agregadora e solidária, não correspondeu ao esperado.

Alterações na conjuntura do mercado de laranja, em razão das geadas na Flórida de 1962-1963, abriram ao mercado brasileiro a possibilidade de exportação de suco, constituindo fator relevante para a instalação na região da primeira agroindústria processadora de sucos cítricos, em $1963^{1}$

Este fato resultou em que, apesar da expansão que se vinha verificando da área cultivada ocupada pela laranja, no estado de São Paulo, dado o período de maturação do pomar, de 3 a 4 anos, à demanda interna existente somou-se a demanda surgida a partir da instalação de agroindústria processadora de citros. A partir daí o preço da laranja oferecido pelo mercado interno se elevou, passando a ser compensador para o produtor direcionar seu produto para esse mercado.

Se a laranja in natura que era comercializada a "bom preço" no mercado externo tinha que obedecer a um padrão de qualidade (tamanho, cor, contextura, etc.), a partir da instalação da fábrica de suco, o produtor poderia obter um preço compensador sem que tivesse que obedecer ao padrão de qualidade imposto pelo mercado externo para a laranja in natura, vendendo sua produção como insumo para a indústria.

Diante dessas alterações, a cooperativa começou a perder força. Reduziram-se as possibilidades da cooperativa, tanto no que se refere à sua interferência sobre a produção quanto no que diz respeito à sua atividade organizadora da comercialização. O procedimento que a cooperativa desenvolvera de receber a laranja no pomar do cooperado (a colheita era organizada pela própria cooperativa) passa a ser adotado pela indústria, como mais um atrativo para o produtor, competindo com a cooperativa. Restaria a atuação da empresa cooperativa na organização dos produtores, porém, agora, subordinados à indústria.

Com o desenvolvimento da indústria processadora de suco - outra fábrica se instala, em $1964^{2}$. Segundo expressão de membro da diretoria, "há transferência de decisão; a cooperativa passa a servir ao interesse da fábrica. A agroindústria, quando se estabelece, modifica toda a relação de produção. Dita as normas". Mesmo assim, torna-se conveniente ao produtor, nesse momento, entregar seu produto diretamente à indústria

Aos efeitos da instalação de indústrias processadoras de sucos cítricos deve-se acrescentar como elemento

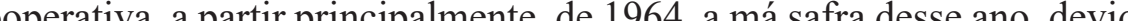
a condições climáticas.

Assim, a cooperativa fundada em 1957 comocooperativa de citricultores, transformadaem 1962 emagrícolamista, sem contudo deixar de ter como atividade principal a citricultura, entra em processo de decadência a partir de 1964

Quando de sua fundação, de acordo com documentos da cooperativa, sua área de atuação abrangia 25 municípios: 17 pertencentes e 8 não pertencentes à Microrregião 242. Em 1960 amplia-se essa área que passa a atingir, além dos municípios abrangidos em 1960, mais os seguintes: Catanduva, Jaú, Novo Horizonte, Ribeirão Preto, Santa Lúcia (que neste ano desmembra-se de Araraquara) e São José do Rio Preto. Em 1969 a reforma de estatutos estipula a redução da área de ação da cooperativa agrícola mista que passa a abranger apenas 12 municípios: Araraquara, Américo Brasiliense, Santa Lúcia, Boa Esperança do Sul, Ibaté, Matão, Nova Europa, Rincão, São Carlos, Tabatinga, Bocaina e Jaú.

Quando de sua passagem de cooperativa de citricultores para agrícola mista, passou a congregar também avicultores; no entanto, estes tinham presença numérica bem pouco significativa. Nessa ocasião, de acordo com o que concedia a legislação em vigor, organizou seção de crédito com o objetivo de complementar os serviços que proporcionava a seus associados. Três grandes seções foram constituídas nesta ocasião: de compras em comum, proporcionava a seus associados. Tres

padronização e vendas e de crédito.

No decorrer de sua existência diversas atividades foram organizadas pela cooperativa. No que diz respeito à sua contribuição, no sentido do desenvolvimento citrícola, induziu ao plantio de novas variedades, através da organização de viveiro de citros. Ainda, com o objetivo de elevar a qualidade da fruta produzida na região desenvolveu, através de seu Departamento Técnico, campanhas de combate às pragas e orientação relativa ao tratamento dos pomares de seus associados. No que se refere à avicultura, não apenas coordenou a aquisição de pintainhos para o avicultor, como também, em complementação a essa atividade, montou seção de abate de de pintainhos para o avicultor, como
frangos, no próprio local de sua sede.

No entanto, apesar dos esforços encetados, por meio de novas estratégias - diversificação de atividades e revisão de área de atuação - esta cooperativa teve sua atuação praticamente paralisada, já em 1967.

Instalada com objetivos voltados principalmente para a exportação da laranja in natura, em função dos preços bem menos compensadores obtidos no mercado interno, ao surgirem as primeiras fábricas de suco - elemento novo no mercado citrícola - as atividades da cooperativa entraram em decadência. De fato, até 1963 sua situação mostrava-se bastante favorável, segundo relato de membro da direção que esteve na liderança da referida empresa desde sua fundação. A partir de 1964 a cooperativa reduz seu ritmo de atividades. Segundo palavras do entrevistado mencionado, "começa a degringolada". Tendo encaminhado o balanço de 1969, no entanto já em 1968 a cooperativa não enviara balancetes ao DAC e em 1970 encerra sua contabilidade. Se a Figura 1 sugere aparente estabilidade, em termos do número de associados, que continuavam incluídos como cooperados, de fato, grande parte deles já havia deixado de se relacionar com a empresa na condição de produtores.

Tendo interferido sobre a organização da produção e da comercialização citrícola da região, no entanto, a cooperativa não soube conduzir suas atividades de modo a acompanhar as próprias condições de mercado. Uma vez modificadas as "regras do jogo", com a elevação de preços no mercado interno e a implantação da indústria processadora, sua atividade foi, gradativamente, sendo posta em xeque. As mudanças no mercado foram mais fortes do que as propostas de agregação e cooperação apregoadas pelo cooperativismo.

Cabe referência ao fato de que, mesmo durante o período inicial de sucesso, a cooperativa procedeu de forma tão ou mais imediatista quanto procederiam, posteriormente, os produtores, nos primeiros anos de elevação dos preços da laranja no mercado interno. De fato, com o intuito de tornar evidente a vantagem cooperativa para 0 produtor, o excedente líquido, de fato lucro (sobras liquidas na terminologia cooperativista) foi quase em sua totalidade devolvido aos associados sob a forma de retorno ${ }^{3}$. Assim, a estratégia de seu líder, no intuito de conseguir adeptos para a causa cooperativista, resultou em elemento negativo para o bom funcionamento da empresa. Posteriormente, na década de 1970, esse mesmo líder - apesar de estar a referida cooperativa

Na verdade, a decisão do destino a ser dado ao retorno é tomada em Assembleia de Associados. Por esta razão, poder-se-ia julgar impreciso ou mesmo incorreto o

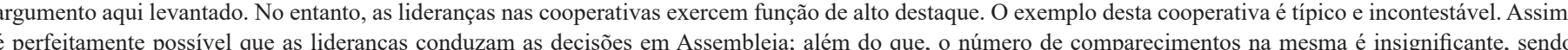
sempre sua realização processada em terceira convocação, por insuficiência de quórum. Esta constante, tíica do funcionamento das cooperativas, quer nos períodos de seu bom funcionamento, quer durante as crises, torna possivel que as decisões sejam assumidas sempre por uma minoria, que em geral sempre esteve encabeçando a empresa. Tal fato implica em que, ao mesmo tempo em que as decisões tendem a ser homogêneas, suas garantias de execução se reduzem 
paralisada - continuava batalhando pelo seu reerguimento e reconhecia as falhas iniciais em que a empresa havia incorrido, sobretudo no que diz respeito à não capitalização, quando de seu bom desempenho inicial.

O principal estimulador da constituição da cooperativa, citricultor e líder cooperativista, reconheceu inúmeras falhas, que poderiam explicar o fracasso dela. Algumas críticas poderiam ser feitas no âmbito da própria cooperativa; outras referir-se-iam ao próprio desenvolvimento e funcionamento do cooperativismo no Brasil. Entre as falhas no âmbito da cooperativa, reconheceu as que se originaram de seu idealismo inicial. De fato, este "idealismo" refletia nada mais nada menos do que o próprio clima de "mito" que deu suporte ao cooperativismo no Brasil.

As causas do fracasso da cooperativa podem ser explicadas pela ausência de planejamento tanto no âmbito da empresa quanto no do Estado, sendo que a primeira só poderia ser evitada através de uma orientação de fato pelos órgãos do governo, com atribuições para tal fim. Sem orientação, pouco poder-se-ia esperar da capacidade gerencial de agricultores que nem mesmo são capazes de organizar a contabilidade em suas fazendas em termos de receitas e despesas. Justamente aí a empresa cooperativa poderia funcionar - com o apoio do Estado - como instrumento de mudança, introduzindo a racionalidade capitalista no setor primário

Através da análise do processo de instalação e funcionamento inicial da cooperativa, pôde-se constatar certa força modificadora dela, sobretudo no que diz respeito à transmissão, a seus associados, de conhecimentos técnicos necessários ao desenvolvimento de sua produção. No entanto, no que diz respeito às relações sociais advindas da associação cooperativa, absolutamente elas se mostravam diferenciadas das demais expressas po não associados.

A observação do processo evolutivo da cooperativa mostrou que, justamente no momento em que a solidariedade pregada pelo cooperativismo se fez necessária, não se fez presente. Assim a análise das crises, por que vinha passando a empresa, pôs em evidencia a ineficácia do esperado "comportamento cooperativista". Ao tomar conhecimento do "abalo" por que passava a cooperativa, resultante da ausência de fidelidade por parte dos associados, constatou-se, então, que os supostos formulados, relativos à possibilidade de contribuição da cooperativa para a tomada de consciência, por parte dos indivíduos, dos mecanismos econômicos a que estão sujeitos, praticamente inexistia. Os associados, sem perceberem os efeitos de sua atitude, no longo prazo, gradetivamente deixavam de entregar sua produção à cooperativa, com a qual haviam assumido compromissos, cedendo-a a preços pouco mais altos à indústria ou a "atravessadores". Tal atitude punha por terra a possibilidade de se pensar numa solidariedade inerente ao cooperativismo ou consolidável a partir dele. Portanto, as possibilidades imputadas às cooperativas, referentes à "reorganização" da solidariedade, mostraram-se falidas, no caso analisado.

Poder-se-ia então pensar que, apesar da inexistência da "solidariedade cooperativista", a empresa poderia exercer funções modificadoras. De fato, as tentativas por ela encetadas, no sentido de melhoria técnica das condições de produção de laranja, pareciam evidenciar aspectos positivos. No entanto, a cooperativa demonstrou sua incapacidade de adaptação à nova situação. Tendo "induzido" o cooperado no sentido de levá-lo a tomar conhecimento de técnicas modernas de produção, não foi capaz ou não teve condições de se reaparelhar diante das modificações por que passavam a produção e a comercialização citrícolas para as quais, de certa forma, também contribuíra.

Não foram criadas condições que tornassem a cooperativa capaz de enfrentar a competição de empresas não cooperativas instaladas na região que, por sua vez, passaram a usufruir das condições favoráveis criadas pela própria cooperativa. Foi esse o legado da cooperativa

Constatou-se que: se a empresa estudada não atuara através da "solidariedade cooperativa", também não soubera proceder como simples empresa que atua dentro de padrões capitalistas. Essa segundaconstatação poderia ser, então, justificada em termos da impossibilidade de uma empresa cooperativa atuar em moldes capitalistas presa a uma legislação "ortodoxa" e desprovida de apoio governamental.

Passadas quatro décadas da realização da investigação, a excessiva valorização de espírito cooperativo e solidário ainda se manifesta na observação de estudiosos das associações cooperativas ou solidárias.

\section{CONSIDERAÇÕES FINAIS}

Através do estudo de caso desenvolvido na cooperativa agrícola mista, que reunia citricultores, pretendiase identificar elementos propiciadores de mudança de mentalidade dos produtores agrícolas associados.

Partiu-se do suposto de que, através das cooperativas, pequenos e médios produtores, atraídos pelo sentimento de "solidariedade" que marcava este tipo de entidade, agregar-se-iam a ela e, de forma gradativa, seriam familiarizados com modernas técnicas de produção, introduzidas através de orientação de órgãos controladores das empresas cooperativas. Enfim, se inicialmente levados às cooperativas por sentimentos mais ou menos difusos de cooperação, através da práxis cooperativa esses produtores teriam a possibilidade de consolidar seu sentimento de "solidariedade", de forma a que obtivessem resultados econômicos compensadores. Dessa forma, a cooperativa viria a representar forma de defesa daqueles que, por não disporem de condições de competitividade, em função de serem pequenos e médios produtores, através da cooperativa passariam a participar com maior "poder de barganha" do jogo das forças de mercado. Portanto, o tipo de empresa analisada funcionaria,sobretudo no meio rural, como entidade que, simultaneamente, desencadearia mudança de "mentalidade", tornando esses produtores - unidos e cooperando entre si - mais competitivos.

Através da análise da constituição, desenvolvimento, auge e declínio da entidade estudada mostraram-se recorrentes alguns fenômenos que, guardadas as devidas especificidades, também foram observados nas cooperativas de café e de cana analisadas na mesma ocasião.

A instalação da cooperativa, longe de se ter processado a partir de uma orientação efetiva, por parte dos órgãos cooperativistas, deveu-se à iniciativa de agricultores que, dispondo de um conhecimento mais ou menos difuso da "realidade", esperavam encontrar, através dela, a solução para seus problemas enquanto produtores.

A função dos órgãos promotores do cooperativismo foi, desde a implantação da cooperativa, a de ratificar a constituição dela, desde que sua organização obedecesse ao estipulado pela legislação. Portanto, seu sucesso esteve, desde o início, vinculado às condições de mercado dos produtos - a laranja o principal - em função de seus fundadores estarem voltados para a produção delae às frágeis possibilidades "gerenciais" de seus fundadores e dirigentes.

Desta forma, as lideranças organizadoras das cooperativas exerceram, desde o início, função de destaque, tendo sido seu entusiasmo o elemento catalizador de adesão para a causa cooperativista. Assim sendo, os "destinos" da empresa estiveram, em parte, na dependência das condições de que dispunham seus organizadores como "dirigentes" das cooperativas.

Também - e esta situação foi observada para as três cooperativas estudadas - as condições de funcionamento variaram em função, entre outras razões, do "significado" do produto a que estavam ligadas, tanto em termos de sua "presença" na produção agrícola da região em questão, quanto no que se refere à posição em que se encontravam no mercado.

Assim sendo, sua atuação se fez sentir a partir das condições existentes, ou seja, suas potencialidades modificadoras estavam limitadas às próprias possibilidades que a região e seus lideres ofereciam.

Portanto, se o conhecimento da realidade, adquirido no cotidiano da atuação dos produtores, a partir do qual as cooperativas analisadas se instalaram, tornava possível que seus dirigentes fossem capazes de conduzir à formulação de soluções pelo menos momentaneamente adequadas, no entanto, à medida em que certas variáveis se alteravam, muitas vezes em decorrência da própria atuação das empresas cooperativas, reduziamse as possibilidades dessasentidadesmanterem suas atividades no mesmo ritmo que vinham, inicialmente, imprimindo a elas.

Este foi o caso típico da cooperativa agrícola mista - de citricultores.Instalada "adequadamente", tendo em vista as condições de comercialização da laranja propiciada pelo mercado externo, as potencialidades da região no que concerne à cultura citrícola e às condições do grupo que a organizou - no entanto, apenas em seu período inicial deu provas de sucesso. Apesar de ter partido se não dos condicionantes básicos, ao menos das potencialidades regionais existentes, a partir de sua instalação, desencadeou alterações significativas sobre a citricultura da região. Voltada para a modernização da cultura citrícola com vistas à elevação de sua produtividade e à melhoria da fruta produzida, também exerceu influência no que se refere à comercialização. No entanto, faltou-lhe "visão empresarial". Liderada segundo os princípios cooperativistas, "adequada" à produção da região em que se localizava, não soube valer-se das condições favoráveis desfrutadas quando do início de sua instalação. Confiante na "solidariedade" de seus associados, não percebeu que por trás da aparente "solidariedade" estavam, justamente, as próprias condições de mercado dos bens que produziam - apresentando, na ocasião, condições favoráveis aos produtores, independentemente da cooperativa. Assim sendo, não poderia desenvolver um tipo de atitude capaz de, antevendo a possível ausência de fidelidade à cooperativa, prevenirse quanto às posições a assumir quando as condições, então favoráveis, sofressem alterações.

Se admitido que as cooperativas de produção ligadas ao setor primário deveriam ser desencadeadoras de mudanças, tanto em relação à introdução de novas técnicas de produção quanto no que se refere à mudança de mentalidade do produtor, dever-se-ia reconhecer, também, que essas funções atribuídas às cooperativas 
somente poderiam ser alcançadas desde que tivesse o suporte de uma orientação precisa de suas atividades.

$\mathrm{Na}$ verdade, no momento em que o estudo se desenvolveu, era frequente o caso dos organizadoresdas cooperativas serem os próprios produtores, na medida em que os órgãos dirigentes das cooperativas apenas mantinham uma atitude de controle, jamais de orientação efetiva e coerente com a realidade.

Seria, então incoerente pensar-se que as "falhas de previsão" observadas na cooperativa estudada seriam características apenas dessa entidade. Seria ilógico atribuir ao agricultor, como organizador da cooperativa, justamente o comportamento que se pretenderia atingir através da própria prática cooperativista. Abandonada sua ação ao sabor das contingências, seria pouco provável que, através da prática não orientada,fossem obtidos os resultados desejados.

Pode ser que, inicialmente, a simples união gerasse resultados benéficos ao funcionamento da empresa Este foi o caso da cooperativaestudada e também das vinculadas ao café e à cana, objeto da investigação no mesmo período. No entanto, desde que suas atividades não estivessem orientadas e planejadas -e este vinha sendo, na época, o grande problema enfrentado pelo cooperativismo no Brasil - as cooperativas mostraram-se pouco flexíveis, incapazes de acompanhar até mesmo as mudanças que elas próprias desencadearam, no caso em questão, a própria dinamização dos produtores.Não se pode, no entanto, negar que a cooperativa desencadeou citricultura na Região de Araraquara, da qual se on órgãos de planejamento traçar as diretrizes básicas orientadoras da atuação e funcionamento da empresa cooperativa. Esta, diretamente vinculada aos organismos governamentais teria, então, não apenas condições de funcionar como empresa "racionalmente" organizada, mas, sobretudo poderia se utilizada como entidade através da qual não apenas o Estado captaria a problemática do setor agrícola, mas também, através dela expediria suas medidas de Política Econômica. As empresas cooperativas poderiam, assim, pelo fato de serem empresas de pessoas e não de capital e ainda em função de congregarem produtores de diversos portes, constituir-se em veículo das decisões governamentais. As condições dos pequenos produtores cooperados, sob este aspecto, poderiam ser melhoresdo que as dosnão cooperados.

$\mathrm{Na}$ verdade, os órgãos aos quais estavam sujeitas as cooperativas, além de serem muito mais fiscalizadores do que orientadores das atividades das referidas empresas, ao fornecerem orientação "teórica" para as cooperativas o faziam muito mais em termos do "mito" cooperativista, do que através de tentativas de "adequar" o cooperativismo à realidade através da qual efetivam-se as relações cooperativistas na região e mesmo no Brasil.

Assim sendo, inspirados em um conceito de bem estar mais ou menos difuso, obtenível através da atuação da empresa cooperativa, os órgãos divulgadores do cooperativismo, no momento em que foi desenvolvida a pesquisa, não foram capazes de perceber que a concretização do bem estar na sociedade capitalista está diretamente vinculada à realização do lucro. Deixada de lado esta evidência, torna-se incoerente a ação modificadora que se pretende instaurar, através das cooperativas. Ao mesmo tempo em que se pretende modificar a mentalidade do produtor agrícola, dinamizando-a pretende-se que ele mantenha-se "tradicionalmente" fiel solidário.

De fato, o principal problema enfrentado pela cooperativa analisada - e ao que parece ela se mostrou representativa do cooperativismo de produção ligado ao setor primário - foi a ausência de planejamento de suas atividades e o excesso de confiança na capacidade de agregação e solidariedade dos cooperados.

A empresa estudada quando de sua fundação, não apenas se organizou a partir de conhecimento bastante difuso da realidade sobre a qual atuaria como, também, no decorrer de sua atividade, nem sempre foi capaz de imprimir à sua organização, enquanto empresa, as "marcas" características do sistema mais amplo com o qual estava envolvida.

\section{REFERÊNCIAS}

ARRUDA, A. P. R. O cooperativismo rural em São Paulo (contribuição ao conhecimento de sua estrutura e posição) - Dissertação (Mestrado). Faculdade de Filosofia, Letras e Ciências Humanas, Universidade de São Paulo, São Paulo, 1972

BERTO, R. M. V. S.; NAKANO, D. N. A Produção Científica nos Anais do Encontro Nacional de Engenharia de Produção: um levantamento de métodos e tipos de pesquisa. Produção, v.9, n.2, p.65-76, 2000

BONNER, A. La planificacioneconomica y el movimiento cooperativo. Buenos Aires: Intercoop, 1960.
Cuadernos de Cultura Cooperativa, n.9).

CASTRO, A B. de (1977). Agricultura e desenvolvimento no Brasil. In

CASTRO, A B. de (1977). Agricultura e desenvolvimento no Br
mia Brasileira. Rio de Janeiro, Forense Universitária, 1969.

7 Ensaios sobre a Econo-

CAUCHICK MIGUEL, P. A. Recomendações na Adoção de Estudo de Caso como Abordagem Metodológica. In: SIMPÓSIO DE ENGENHARIA DE PRODUÇ̃̃O, 12., Anais... SIMPEP - Bauru, SP, Brasil, 7 a 9 de Novembro de 2005. CD ROM $12 \mathrm{p}$.

CITROSUCO. Nossa História. Disponível em http://www.citrosuco.com.br/nossa-historia.html. Acesso em $\underline{30 / / 07 / 2017 .}$.

CORREA, A. M. M. A história social de Araraquara. Tese (Doutorado em Ciências Humanas) - Faculdade de Filosofia, Letras e Ciências Humanas, USP, 1968.

DEPARTAMENTO DE ASSISTÊNCIA AO COOPERATIVISMO (DAC). Esboço histórico do cooperativismo em São Paulo. v.1, n. 93, ago. 1941.

DEPARTAMENTO DE ASSISTÊNCIA DO COOPERATIVISMO (DAC). Um decênio de cooperativismo, n. 116, jul. 1943.

DEPARTAMENTO DE ASSISTÊNCIA DO COOPERATIVISMO (DAC). Realizações cooperativistas v.1, n. 185 , abr.1951a.

DEPARTAMENTO DE ASSISTÊNCIA DO COOPERATIVISMO (DAC). Realizações cooperativistas v.1, n. 186 , maio $1951 b$

DEPARTAMENTO DE ESTATÍSTICA DO ESTADO DE SÃO PAULO (DEESP). Coleta (in loco) e organização de dados não publicados referentes à produção agrícola de municípios selecionados do estado de São Paulo.

DESROCHES, H. Coopération et development: Mouvements coopératifs et stratégie du développment. Paris: Institute d'étude du développment économique et social de l'université de Paris (PUF), 1964.

FAUQUET, G. "Le secteur coopératif". Archives internationales de sociologie de la coopération, n. 17, 1965.

GUELFAT, I. La cooperation devant la Science économique. Paris: Presses Universitaires de France, 1966. (Collection "Tiers Monde").

INSTITUTO BRASILEIRO DE GEOGRAFIA E ESTATÍSTICA - IBGE (Departamento de Geografia). Divisão do Brasil em micro-regiões homogêneas 1968. Rio de Janeiro: Ministério do Planejamento e Coordenação Geral, 1970.

INSTITUTO DE ECONOMIA AGRÍCOLA (IEA). Desenvolvimento da agricultura paulista. São Paulo: Secretaria da Agricultura, 1971.

INSTITUTO NACIONAL DE COLONIZAÇÃO E REFORMA AGRÁRIA (INCRA). Cooperativismo no Brasil. 1973.

JOHNSTON, B.F.; MELLOR, J.W. The role of agriculture in development. American Economic Review, v.51, n.4, p. 566-593, 1961 .

Revista Brasileira Multidisciplinar - ReBraM vol 20, (supl.) n.1 - Araraquara 200 anos 
Cooperativismo e cooperativa no desenvolvimento....

LAMBERT, P. La doctrine cooperative. 3e éd. Bruxelles : Les Propagateurs de la coopération. 1964

LASSERE, G. La cooperation. Paris: PUF, 1962.

LAVERGNE, B. La revólución cooperativael socialismo de ocidente. México: ImprensaUniversitaria, 1962.

MARTINS, R. A. Abordagens Quantitativa e Qualitativa. In: CAUCHICK MIGUEL, P. A. (Org.) Metodologia de Pesquisa em Engenharia de Produção e Gestão de Operações. Rio de Janeiro: Elsevier, 2010, p. 45-61.

MIRANDA, V. M. H. Doutrina e Empresa Cooperativas: contribuição para o estudo do cooperativismo na "Região de Araraquara". 1973. 233 p. Tese (Doutorado em Economia). Departamento de Filosofia e Ciências Humanas da Faculdade de Filosofia, Ciências e Letras de Araraquara. Araraquara, 1973.

MLADENATZ, G. Historia de las doctrinas cooperativas. Trad. de Luis Nuevomena, México: América, 1944.

NAKANO, D. Métodos de Pesquisa adotados na Engenharia de Produção e Gestão de Operações. In: CAUCHICK MIGUEL, Paulo A. (Org.) Metodologia de Pesquisa em Engenharia de Produção e Gestão de Operações. Rio de Janeiro: Elsevier, 2010, p. 63-72.

PINHO, D. B. Dicionário de Cooperativismo. 2 ed. São Paulo: USP, 1962.

PINHO, D. B. La coopération en Régime capitaliste et en Régime socialiste. Revue de études coopératives, n. 131, Paris, 1963a.

PINHO, D. B. Cooperativas e desenvolvimento econômico. Boletim n. 289. Cadeira de Economia Política e História das Doutrinas Econômicas, FFCL da USP. São Paulo: USP, 1963b.

PINHO, D. B. Cooperativismo e desenvolvimento das zonas rurais do Estado de São Paulo. São Paulo: Comissão Interestadual da Bacia Paraná-Uruguai, 1964a.

PINHO, D. B. Cooperativismo e problemas de desenvolvimento regional. Boletim n. 299. Cadeira de Economia Política e História das Doutrinas Econômicas. FFCL da USP. São Paulo: USP, 1964b.

PINHO, D. B. Situação atual do cooperativismo no Brasil. São Paulo: Departamento de Assistência ao Cooperativismo, 1965.

PINHO, D. B.A doutrina cooperativa nos regimes capitalista e socialista: suas modificações e sua utilidade. 2. ed. São Paulo: Pioneira, 1966.

PINHO, D. B. (Org.). A problemática do cooperativismo no desenvolvimento econômico. República Federal da Alemanha, São Paulo: Fundação Friederich Neumann, Bonn-Bad Godsbag, 1973.

RODRIGUES, L. M. A importância das cooperativas do setor agrícola no desenvolvimento cooperativista brasileiro. Brasil: Escritório Técnico de Agricultura (ETA), 1966 (mimeo).

ROJAS CORIA, R. Introducción ao estúdio del cooperativismo. México, 1961.

SÃO PAULO. Secretaria da Agricultura. Divisão de Economia Rural. Estado e tendências da agricultura paulista. Agricultura em São Paulo, n. 10, v. 5-6, p. 1-61, 1963.
COSTA, Vera Mariza H. de Miranda.

SÃO PAULO. Secretaria da Agricultura. Divisão de Economia rural. Diagnóstico da agricultura paulista. Agricultura em São Paulo, n. 14, v. 5-6, p. 1-47, 1967.

SÃO PAULO. Secretaria da Agricultura. Desenvolvimento agrícola: um grande desafio. Campinas: Coordenaria de Assistência Técnica Integral (CATI), 1972.

SINGER, P. Introdução à Economia Solidária,São Paulo: Fundação Perseu Abramo, 2002.

TAVARES, M.C. Da Substituição de Importações ao Capitalismo Financeiro. Rio de Janeiro, Zahar, 1973.

TURRIONI, J. B.; MELlO, C. H. P. Metodologia de Pesquisa em Engenharia de Produção: estratégias, métodos e técnicas para condução de pesquisas quantitativas e qualitativas. Itajubá: UNIFEI, 2012.

YIN, R. K. Estudo de caso: planejamento e métodos. Trad. D. Grassi. 3. ed. Porto Alegre: Bookman, 2005. 